\section{Effect of production process and high-pressure processing on viability of Listeria innocua in traditional Italian dry-cured coppa}

\author{
Roberta Taddei, ${ }^{1}$ Federica Giacometti, ${ }^{2}$ \\ Lia Bardasi, ${ }^{1}$ Paolo Bonilauri, ${ }^{3}$ \\ Mattia Ramini, ${ }^{1}$ Maria Cristina \\ Fontana, ${ }^{1}$ Patrizia Bassi, ${ }^{1}$ \\ Sara Castagnini, ${ }^{1}$ Francesco Ceredi, ${ }^{1}$ \\ Maria Francesca Pelliconi, ${ }^{1}$ \\ Andrea Serraino, ${ }^{2}$ Federico Tomasello, ${ }^{2}$ \\ Silvia Piva, ${ }^{2}$ Elisabetta Mondo, ${ }^{2}$ \\ Giuseppe Merialdi ${ }^{1}$ \\ ${ }^{1}$ Istituto Zooprofilattico Sperimentale \\ delle Lombardia e dell'Emilia Romagna, \\ Sede Territoriale di Bologna; \\ ${ }^{2}$ Dipartimento di Scienze Mediche \\ Veterinarie, Università di Bologna, \\ Ozzano dell'Emilia (BO); ${ }^{3}$ Istituto \\ Zooprofilattico Sperimentale delle \\ Lombardia e dell'Emilia Romagna, Sede \\ Territoriale di Reggio Emilia, Reggio \\ nell'Emilia, Italy
}

\begin{abstract}
In this study the effect of the application of High Pressure Treatment (HPP) combined with four different manufacturing processes on the inactivation of Listeria innocua, used as a surrogate for L. monocytogenes, in artificially contaminated coppa samples was evaluated in order to verify the most suitable strategy to meet the Listeria inactivation requirements needed for the exportation of dry-cured meat in the U.S. Fresh anatomical cuts intended for coppa production were supplied by four different delicatessen factories located in Northern Italy. Raw meat underwent experimental contamination with Listeria innocua using a mixture of 5 strains. Surface contamination of the fresh anatomical cuts was carried out by immersion into inoculum containing Listeria spp. The conditions of the HPP treatment were: pressure $593 \mathrm{MPa}$, time 290 seconds, water treatment temperature $14^{\circ} \mathrm{C}$. Listeria innocua was enumerated on surface and deep samples post contamination, resting, ripening and HPP treatment. The results of this study show how the reduction of the microbial load on coppa during the production process did not vary among three companies $(\mathrm{P}>0.05)$ ranging from 3.73 to $4.30 \log \mathrm{CFU} / \mathrm{g}$, while it was significantly different $(\mathrm{P}<0.01)$ for the fourth company (0.92 log CFU/g). HPP treatment resulted in a significant $(\mathrm{P}<0.01)$ deep decrease of $L$.
\end{abstract}

innocua count with values ranging between 1.63-3.54 log CFU/g with no significant differences between companies. Regarding superficial contamination, HPP treatment resulted significant $(\mathrm{P}<0.01)$ only in Coppa produced by two companies. The results highlight that there were processes less effective to inhibit the pathogen; in particular for company D an increase of L. innocua count was shown during processing and HPP alone cannot be able to in reaching the Listeria inactivation requirements needed for exportation of dry-cured meat in the U.S. According to the data reported in this paper, HPP treatment increases the ability of the manufacturing process of coppa in reducing Listeria count with the objective of a lethality treatment.

\section{Introduction}

Listeria monocytogenes is a foodborne pathogen that causes listeriosis, a relatively rare but potentially fatal illness. Healthy individuals are usually not susceptible to $L$. monocytogenes, unlike those with compromised immune system such as elderly, pregnant women and newborns, in which mild to severe consequences can be observed (Jordan and McAuliffe, 2018). In 2018 there were 2,549 confirmed human cases of listeriosis in the EU, corresponding to a notification rate of 0.47 cases per 100,000 population. In the last years (period 2014-2018) there has been a statistically significant increasing trend of confirmed listeriosis cases in the EU/EEA, with a high case fatality $(15.6 \%)$, which makes listeriosis one of the most serious foodborne diseases under EU surveillance (EFSA and ECDC, 2019). In the United States it has an incidence of 0.3 cases per 100,000 population (Tack et al., 2019).

L. monocytogenes, being ubiquitous in the environment, can contaminate foodprocessing plants, survive for long periods due to its capability to resist to various stresses, such as exposure to sanitizers, $\mathrm{pH}$ and temperature, and form biofilm. It mainly represents a problem for the Ready-To-Eat (RTE) food industry, as there is no lethal treatment between production and consumption ( Gray et al., 2018; Jordan and McAuliffe, 2018). Over the 2016-2018 period, samples from pig meat were by far the main matrix tested for $L$. monocytogenes in the EU, $59.9 \%$ in 2018 , out of the 24,814 RTE pig meat products tested, $1.3 \%$ was positive for L. monocytogenes, $1.4 \%$ at production level and $0.8 \%$ at retail level (EFSA and ECDC, 2019). Several authors evaluated the presence of $L$. monocytogenes in RTE pig meat products such as dry-cured
Correspondence: Federico Tomasello, Dipartimento di Scienze Mediche Veterinarie, Università di Bologna, Via Tolara di Sopra $\mathrm{n}$. 50, 40064 Ozzano dell'Emilia (BO), Italy.

E-mail: federico.tomasello4@unibo.it

Key words: Dry-cured meat products, HPP, Listeria spp.

Contributions: The authors contributed equally.

Conflict of interest: The authors declare no conflict of interest.

Funding: None.

Received for publication: 25 May 2020.

Revision received: 18 June 2020

Accepted for publication: 24 Jume 2020

This work is licensed under a Creative Commons Attribution-NonCommercial 4.0 International License (CC BY-NC 4.0).

(C) Copyright: the Author(s), 2020

Licensee PAGEPress, Italy

Italian Journal of Food Safety 2020; 9:9133

doi:10.4081/ijfs.2020.9133

ham (Garriga et al., 2004; Merialdi et al., 2015), dry-cured pork loins (Morales-Partera et al., 2017) and others dry-cured pig meat products including coppa, bacon and smoked speck (Meloni et al., 2009).

Coppa is a typical Italian cured pork meat product consisting of a whole piece of meat obtained from the neck muscles of heavy pigs, traditionally made in the provinces of Parma and Piacenza (Emilia Romagna Region, Northern Italy). Characteristics and product processing information can be found in the PDO specifications

(http://www.salumidoppiacentini.com/coppa-dp/index.jspeldoc?IdC=160\&IdS=168\&tipo_cli ccato $=0 \&$ tipo $\_$padre $=0 \&$ nav $=1 \&$ css $=$ generico dop.css\&menu $=1$;

http://www.coppadiparmaigp.com/disciplina re-di-produzione-igp-coppa-parma/) or in the few published papers (Zanardi et al., 2000; Busconi et al., 2014). The production process includes, after deboning, halfslicing, and trimming the anatomical cut, one or two salting procedures, using a mixture of salt, additives, and spices. Meat is massaged manually or mechanically, by a meat tumbling machine, in order to distribute the salting mixture evenly. Salting is generally followed by storage at low temperatures for a few days on steel trays (cold rest). After cold resting the meat is wrapped and tied and then exposed to higher temperatures and lower relative humidity, in order to reduce moisture. The last step consists in ripening, 
which takes several weeks, at a lower temperature and higher relative humidity than drying, to reach the desired characteristics of the product. The production processes applied in this work are summarized in Table 1.

Contamination of dry-cured meat products by $L$. monocytogenes may result from superficial contamination of the fresh anatomical cuts, both during slaughtering and production and/or from crosscontamination in case of manipulation by contaminated operators or contact with contaminated equipment or surfaces.

The current EU regulation for $L$. monocytogenes, Regulation (EC) No. 2073/2005 (European Commission, 2005), admits different levels of presence depending on whether or not the RTE product supports the growth of $L$. monocytogenes (products with $\mathrm{pH} \leq 4,4$ or $a_{w} \leq 0,92$, products with $\mathrm{pH} \leq 5,0$ and $a_{w} \leq$ 0,94 and products with a shelf-life of less than five days are considered non supporting its growth). In products supporting its growth EU regulation requires the absence (in $5 \times 25 \mathrm{~g}$ samples) before the food has left the immediate control of the food business operator, and levels $<100 \mathrm{CFU} / \mathrm{g}$ (in $5 \times 25 \mathrm{~g}$ samples) for products already placed on the market during their shelf life; in RTE products that do not sustain its growth it is supposed to be $<100 \mathrm{CFU} / \mathrm{g}$ (in $5 \times 25 \mathrm{~g}$ samples) at production and throughout the defined shelf-life. Differently in the U.S. the regulation in place applies a zero tolerance approach for RTE products, regardless of whether or not they support the growth of the pathogen (Food Safety Inspection Service, 2015). The U.S. Department of Agriculture Food Safety and Inspection Service (USDA/FSIS) requires the establishments producing dry-cured meat products to include a process addressing lethality of $L$. monocytogenes to consider their products safe for consumption, defining lethality as a process or combination of processes that ensures a specific, significant reduction in the number pathogens in the product .

High hydrostatic pressure (HPP) is a non-thermal food preservation technology used to extend the shelf life and to enhance the microbiological safety without altering the organoleptic and nutritional characteristics of treated products. It is an emerging technology with applications to a wide variety of food, mainly used as a final sanitization measure after production and/or packaging procedures (Hugas et al., 2002). HPP has been successfully applied for the treatment of a wide variety of food including meat-based products (cooked and dry ham, etc.), fish, pre-cooked dishes and fruit, vegetables and juices (Sandra et al., 2004; Rastogi et al., 2007; Zhang and Mittal, 2008; Van Hekken et al., 2013). Several treated RTE dry-cured meat products such as ham and salami are currently available on the market in Europe, U.S.A., Japan, and Canada (Tao et al., 2014).

In this study it was evaluated the effect of the application of HPP combined with different manufacturing processes on the inactivation of Listeria innocua, used as a surrogate for L. monocytogenes ( $\mathrm{Hu}$ and Gurtler, 2017), in artificially contaminated coppa samples, in order to verify the ability of the combined processes to meet the requirements needed for exportation to the U.S.

\section{Materials and Methods}

\section{Inoculum composition}

The L. innocua inoculum culture was prepared using a mixture of 5 strains: IZSLER 111373/1 and IZSLER 111373/2 isolated from industrial site (superficial swab collected in pork meat transformation plant), IZSLER 257529/1 isolated from fresh pork sausages, IZSLER 257529/2 isolates from fresh swine meat and the reference strain ATCC $33090,100 \mu \mathrm{L}$ of a stock culture (stored in $20 \%$ glycerol at $-80^{\circ} \mathrm{C}$ ) of each strain were transferred to $10 \mathrm{ml}$ Brain Heart Infusion (BHI) broth and incubated for $24 \mathrm{~h}$ at $30^{\circ} \mathrm{C}$. Subsequently, an aliquot of $100 \mu \mathrm{l}$ was transferred to $1000 \mathrm{~mL} \mathrm{BHI}$ broth and incubated at $12^{\circ} \mathrm{C}$ for $72 \mathrm{~h}$ (Merialdi et al., 2015).

Just before contamination, the 5 subcultures of L. innocua were mixed in equal volume and the resulting culture was checked by enumeration on selective agar.

\section{Samples contamination and produc- tion process}

Fresh anatomical cuts intended for Coppa production were supplied by four different artisanal delicatessen factories located in Northern Italy herein named A, B, $\mathrm{C}$ and $\mathrm{D}$. Raw meats, with a weight ranging from 2.5 to $3 \mathrm{~kg}$, underwent experimental contaminations with L. innocua. The anatomical cuts were contaminated by immersion for 10 minutes into the inoculum containing L. innocua, then dried for 30 minutes at room temperature.

The detailed processing procedures applied are detailed in Table 1. The protocols included one (company A and D) or two (company B and C) salting procedures with salting mixtures being supplied by the four companies. In all the protocols, meat samples underwent one or more steps in meat tumbling machine in order to get a homogenous distribution of the salting mixture. Coppa samples were processed according to the producer's specifications (Table 1) undergoing a resting phase (9 to 32 days at $1-8^{\circ} \mathrm{C}$ ), a drying phase (3 to 7 days at $12-27^{\circ} \mathrm{C}$ ), and a ripening phase (44 to 69 days at $14-21^{\circ} \mathrm{C}$ ).

After salting, coppa samples were singularly packed in synthetic casing and, at the end of the maturation period, they were separately transferred to nylon-polyethylene bags and vacuum sealed.

\section{HPP treatment}

For each contamination study, 5 vacuum-packed Coppa samples were exposed to HPP treatment and 5 samples acted as control. For the HPP treatment the following settings were applied: pressure $593 \mathrm{MPa}$, time 290 seconds, water treatment temperature $14^{\circ} \mathrm{C}$, product temperature at the time of treatment $4^{\circ} \mathrm{C}$. The pressure holding treatment time in this study did not include the pressure increase time or the decompression time. The water temperature during the process started from $14^{\circ} \mathrm{C}$, grew until $32^{\circ} \mathrm{C}$ during the treatment, and

Table 1. Experimental scheme including the number of analyzed test units for each processing step, sampling characteristics and scheduled analyses.

\begin{tabular}{|c|c|c|c|c|}
\hline & Company A & Company B & Company C & Company D \\
\hline Anatomic cut weight (Kg) & 2.7 & 2.5 & 3 & $2.5 / 3$ \\
\hline Number of salting & 1 & 2 & 2 & 1 \\
\hline Resting length (days)/temperatures & $14 / 3-5^{\circ} \mathrm{C}$ & $32 / 3-5^{\circ} \mathrm{C}$ & $27 / 1-4^{\circ} \mathrm{C}$ & $9 / 6-8^{\circ} \mathrm{C}$ \\
\hline Drying length (days)/temperatures & $5 / 20^{\circ} \mathrm{C}$ & $7 / 27^{\circ} \mathrm{C}$ to $14^{\circ} \mathrm{C}$ & $6 / 22^{\circ} \mathrm{C}$ to $16^{\circ} \mathrm{C}$ & $3 / 12-27^{\circ} \mathrm{C}$ \\
\hline Ripening length (days)/temperatures & $51 / 15^{\circ} \mathrm{C}$ & $40 / 14-18^{\circ} \mathrm{C}+24 / 17-21^{\circ} \mathrm{C}$ & $69 / 14-16^{\circ} \mathrm{C}$ & $44 / 14^{\circ} \mathrm{C}$ to $16^{\circ} \mathrm{C}$ \\
\hline
\end{tabular}


immediately returned to $14^{\circ} \mathrm{C}$ after the end of pressure stress.

\section{Sampling procedure}

After the inoculation with L. innocua strains, for each challenge test, a total of 3 samples for each sampling time, inoculum (T0), post resting (T1), and a total of 5 samples post ripening (Tend) and post HPP treatment (THPP) were collected and analyzed for the determination of $\mathrm{pH}$ and $a_{w}$ values and the evaluation of $L$. innocua count. The analyses carried out for this study were made both on the surface and in depth of coppa samples. Superficial samples consisted of three squares of approximately $3 \times 3 \mathrm{~cm}$ length and about $0.3 \mathrm{~cm}$ thickness to get a final weight of $25 \mathrm{~g}$, excided from apical, central and terminal positions of each coppa. For deep samples, coppa was immersed for 60 seconds in boiling water, then a $25 \mathrm{~g}$ sample was extracted from the depth of coppa (Bonilauri et al., 2004).

\section{Physicochemical analysis}

Water activity $\left(a_{\mathrm{w}}\right)$ was measured with AquaLab series 4 Model TE instrument, in accordance with ISO 21807:2004 (ISO, 2004). pH was evaluated through Mettler Toledo LE427 glass electrode probe connected to pHenomenal PC5000 L (VWR) $\mathrm{pH} /$ conductivity meter. Weight loss values (expressed as percentage of the initial weight) were determined throughout the production process, on three samples for each contamination study.

\section{Microbiological analysis}

Before inoculation anatomical cuts were controlled for the absence of Listeria spp. following ISO 11290-1:1996/Amd 1:2004 (ISO, 2004) protocol intended for $L$. monocytogenes detection, excepting that suspected colonies were confirmed by biochemical miniaturized tests (API Listeria kit; BioMérieux, France). For L. innocua enumeration, samples were diluted $1 / 10$ in Buffered Peptone Water (homemade) and homogenized in stomacher for $60 \mathrm{~s}$. Ten-fold serial dilutions were plated onto ALOA agar (Biolife, Milan, Italy) and incubated at $37^{\circ} \mathrm{C}$ for $48 \mathrm{~h}$. Suspected colonies were confirmed by biochemical miniaturized tests (API Listeria kit; BioMérieux, France). In samples below the quantification limit (10 CFU/g), the qualitative analysis was carried out as described before. Results of $L$. innocua counts were expressed in $\mathrm{CFU} / \mathrm{g}$ and converted into Log10 CFU/g.

\section{Data analysis}

For comparison between control and treated samples, if the pathogen resulted detectable but not quantifiable in enumeration analysis (under the limit of quantification: $\mathrm{LOQ}=10 \mathrm{CFU} / \mathrm{g}$ ), it was assigned the value of $9 \mathrm{CFU} / \mathrm{g}$ (corresponding to $\log _{10} 9=0.95 \log \mathrm{CFU} / \mathrm{g}$ ) (EFSA, 2010).

To compare the level of the pathogen observed during processing steps and post HPP treatment two way ANOVA test, was used; level 1 was Company productive process (A, B, C, D) and level 2 consisted in productive phases; (T0) inoculum, (T1) post resting, (Tend) post ripening, and (THPP) post HPP treatment. When statistically significant differences were detected, one- way ANOVA and post hoc pairwise comparison across levels were performed by using Tukey's test. Surface and deep contaminations were compared separately.

The statistical analyses were carried out using the computer software program STATA 7.0 (STATA Corporation, College Station, TX, USA). Significance was established at $\mathrm{P}<0.05$.

\section{Results}

Number of salting, resting, lengths and temperatures of resting, drying and ripening phases were different for the four production processes, as reported in Table 1, resulting in dry-cured coppa with different physicochemical characteristics ( $\mathrm{pH}$ and $a_{\mathrm{w}}$ values are summarized in Table 2): before resting, the $\mathrm{pH}$ and $a_{w}$ values ranged from 5.93 to 6.40 and from 0.994 to 0.997 respectively; the resting phase had a variable length between 9 and 32 days and led the $\mathrm{pH}$ and $a_{w}$ values from 5.58 to 6.20 and from 0.933 to 0.972 respectively on surface samples and from 5.62 to 6.03 and from 0.972 to 0.979 on deep samples. After ripening, which also had different durations across the four companies (44 to 69 days), observed $\mathrm{pH}$ values ranged from 5.66 to 6.61 on surface and 5.61 to 6.13 in depth, whereas $a_{w}$ values were reduced by 0.892 to 0.922 and 0.916 to 0.925 on surface and in depth respectively (Table 2 ).

The initial concentration, obtained through artificial contamination, ranged from 7.11 to $7.60 \log$ CFU/g of L. innocua into superficial samples (Table 3).

Table 2. Results of chemicophysical analysis differentiated for manufacturing company carried out in superficial (Sup) and deep (Deep) samples: it is reported the mean value of the obtained measurements followed by the standard deviation into brackets.

\begin{tabular}{|c|c|c|c|c|c|c|c|c|c|c|c|c|c|c|c|c|}
\hline & \multicolumn{4}{|c|}{ Company A } & \multicolumn{4}{|c|}{ Company B } & \multicolumn{4}{|c|}{ Company C } & \multicolumn{4}{|c|}{ Company D } \\
\hline & $\mathrm{pH}_{\text {Sup }}$ & $a_{\text {wSup }}$ & $\mathrm{pH}_{\text {Deep }}$ & $a_{w D e e p}$ & $\mathrm{pH}_{\text {Sup }}$ & $a_{\text {wSup }}$ & $\mathrm{pH}_{\text {Deep }}$ & $a_{w D e e p}$ & $\mathrm{pH}_{\text {Sup }}$ & $a_{\text {wSup }}$ & $\mathrm{pH}_{\text {Deep }}$ & $a_{\text {wDeep }}$ & $\mathrm{pH}_{\text {Sup }}$ & $a_{\text {wSup }}$ & $\mathrm{pH}_{\text {Deep }}$ & $a_{\text {wDeep }}$ \\
\hline TO & $5.95(0.07)$ & $0.997(0.001)$ & N.D. & N.D. & $6.40(0.12)$ & $0.997(0.001)$ & N.D. & N.D. & $5.99(0.25)$ & $0.994(0.002)$ & N.D. & N.D. & $5.93(0.12)$ & $0,995(0.002)$ & N.D. & N.D. \\
\hline $\mathrm{T} 1$ & $6.04(0.10)$ & $0.959(0.009)$ & $6.03(0.16)$ & $0.979(0.003)$ & $6.20(0.18)$ & $0.933(0.008)$ & $5.92(0.12)$ & $0.973(0.005)$ & $5.86(0.13)$ & $0.964(0.038)$ & $5.62(0.15)$ & $0.972(0.002)$ & $5.58(0.05)$ & $0.972(0.001)$ & $5.75(0.09)$ & $0.976(0.005)$ \\
\hline Tend & $5.66(0.18)$ & $0.892(0.017)$ & $5.61(0.13)$ & $0.924(0.005)$ & $6.61(0.23)$ & $0.922(0.005)$ & $6.13(0.16)$ & $0.925(0.006)$ & $6.05(0.19)$ & $0.904(0.019)$ & $5.80(0.05)$ & $0.916(0.010)$ & $6.20(0.05)$ & $0.914(0.002)$ & $5.99(0.08)$ & $0.924(0.007)$ \\
\hline
\end{tabular}

Table 3. Mean value log CFU/g (standard deviation) of L. innocua. (L) enumeration analyses carried out in superficial (Sup) and deep (Deep) Samples.

\begin{tabular}{|c|c|c|c|c|c|c|c|c|}
\hline & \multicolumn{2}{|c|}{ Company A } & \multicolumn{2}{|c|}{ Company B } & \multicolumn{2}{|c|}{ Company C } & \multicolumn{2}{|c|}{ Company D } \\
\hline & $L_{\text {Sup }}$ & $L_{\text {Deep }}$ & $L_{\text {Sup }}$ & $L_{\text {Deep }}$ & $L_{\text {Sup }}$ & $L_{\text {Deep }}$ & $L_{\text {Sup }}$ & $L_{\text {Deep }}$ \\
\hline TO & $7.11^{\mathrm{A}}(0.19)$ & N.D. & $7.34^{\mathrm{A}}(0.24)$ & N.D. & $7.54 \mathrm{~A}(0.20)$ & N.D. & $7.60^{\mathrm{A}}(0.12)$ & N.D. \\
\hline $\mathrm{T} 1$ & $6.65^{\mathrm{A}, \mathrm{x}}(0.27)$ & $5.30^{\mathrm{Ay}}(0.56)$ & $5.95^{\mathrm{B}, \mathrm{x}}(0.23)$ & $4.23^{\mathrm{A}, \mathrm{y}}(0.29)$ & $6.02 \mathrm{~B}, \mathrm{x}(0.39)$ & $4.51^{\text {Ay }}(2.02)$ & $5,78^{\mathrm{B}, \mathrm{x}}(0.30)$ & $2.31^{\mathrm{A}, \mathrm{y}}(0.58)$ \\
\hline Tend & $3.85^{\mathrm{B}, \mathrm{x}}(0.51)$ & $4.37^{\mathrm{A}, \mathrm{x}}(0.80)$ & $4.34^{\mathrm{C}, \mathrm{x}}(0.51)$ & $4.20^{\mathrm{A}, \mathrm{x}}(0.58)$ & $4.65 \mathrm{C}, \mathrm{x}(0.56)$ & $3.94^{\mathrm{A}, \mathrm{x}}(0.25)$ & $7.62^{\mathrm{C}, \mathrm{x}}(0.24)$ & $4.54^{\text {B,y }}(1.52)$ \\
\hline THPP & $3.38^{\mathrm{B}, \mathrm{x}}(0.45)$ & $1.80^{\sharp \mathrm{B}, \mathrm{y}}(0.91)$ & $3.60^{\mathrm{D}, \mathrm{x}}(0.30)$ & $1.71^{\mathrm{B}, \mathrm{y}}(0.26)$ & $3.24 \mathrm{D}, \mathrm{x}(0.41)$ & $2.31^{\mathrm{B}, \mathrm{y}}(0.51)$ & $6.68^{\mathrm{C}, \mathrm{x}}(1.37)$ & $1.00 * C, y(0.10)$ \\
\hline
\end{tabular}

N.D.: Not Determined; \# in 2 out of 5 replicates value 0,95 was assumed since pathogens were detected but not countable; * in 4 out of 5 replicates value 0,95 was assumed since pathogens were detected but not countable. In each column, different capital letters mean significant differences between $L$. innocua contamination evaluated at each sampling step. Significant (x,y) or not significant (x,x) differences between surface and deep contamination, separately evaluated for each step and each company. 
Throughout the early phases of the four production processes, the progressive contamination of deeper parts of the anatomical cuts by inoculated bacteria took place, seemingly facilitated by the use of the meat tumbling machine in concomitance with salting. The first examinations were made at the end of the resting phase, obtaining values for deep contamination comprised between 2.31 and $5.30 \log \mathrm{CFU} / \mathrm{g}$ (Table 3).

The overall superficial reduction resulted of 3.73 to $4.30 \mathrm{log} \mathrm{CFU} / \mathrm{g}$ for companies A, B, C and $0.92 \log \mathrm{CFU} / \mathrm{g}$ for company D. Table 4 reports details of $L$. innocua count reduction showing how the reduction of the microbial load on the surface of the coppa during the production process was not different among companies $\mathrm{A}, \mathrm{B}$ and $\mathrm{C}(\mathrm{P}>0.05)$ ranging from 2.89 to $3.26 \log \mathrm{CFU} / \mathrm{g}$, while it was significantly different $(\mathrm{P}<0.01) \quad(-0,02 \log \mathrm{CFU} / \mathrm{g})$ for company D (Table 4). Similarly, the microbial reduction occurred in depth during drying and ripening process, resulting between 0.03 and $0.93 \log \mathrm{CFU} / \mathrm{g}(\mathrm{P}>0.05)$ for companies A, B, C while an increase of L. innocua count (2.23 log $\mathrm{CFU} / \mathrm{g})$ was shown for company $\mathrm{D}(\mathrm{P}<0.01)$.

HPP treatment resulted in a significant $(\mathrm{P}<0.01)$ deep decrease of L. innocua with values ranging between 1.63-3.54 log CFU/g (Table 4) with no significant differences between companies. Regarding superficial contamination HPP treatment resulted significant $(\mathrm{P}<0.01)$ only in companies $\mathrm{B}$ and $\mathrm{C}$.

\section{Discussion and Conclusions}

This study reports data of 4 challenge tests performed on Italian dry-cured coppa, produced by following four different companies' procedures, and subsequently treated with HPP in order to verify the ability of the overall procedure to obtain a lethal process for Listeria.

L. innocua reduction during curing did not show any significant difference between companies $\mathrm{A}, \mathrm{B}, \mathrm{C}(\mathrm{P}>0.05)$ with values ranging from 2.89 to $3.26 \log \mathrm{CFU} / \mathrm{g}$ (Table 4); similar results have been shown by other authors in several dry-cured meat products. In particular a reduction of $4.0 \mathrm{log} \mathrm{CFU} / \mathrm{g}$ in dry-cured ham after 69 days of curing was observed by Reynolds et al. (2001), and a 2.5 $\log \mathrm{CFU} / \mathrm{g}$ decrease was reported in drycured Serrano ham after 60 days of ripening (Montiel et al., 2020), while Barbuti et al. (2009) reported after 108 days of ripening a decrease of L. monocytogenes of $4.5 \mathrm{CFU} / \mathrm{g}$ in Italian Parma ham. Differences with the values obtained in this study can be addressed mainly to different products characteristics and different production processes.

In the early phase of the production process, the decrease of $L$. innocua in companies $\mathrm{A}, \mathrm{B}$ and $\mathrm{C}$ could primarily be related to the salting treatment to which the anatomical cuts were exposed as it was observed a higher reduction in the two processes that included double salting, while in the subsequent phases the loss of microbial vitality could mainly be related to the progressive reduction of the $a_{\mathrm{w}}$ values correlated with the weight loss of the product.

Differently, values obtained from company $\mathrm{D}$, in terms of $L$. innocua reduction after resting $(-1.84 \log \mathrm{CFU} / \mathrm{g})$ and at the end of the process $(-0,02 \log \mathrm{CFU} / \mathrm{g})$, were significantly lower than the others, (see Table 4), probably because of shorter resting, drying and ripening phases. Several authors reported how a longer maturation period leads to higher reduction of pathogenic bacteria: it was demonstrated that a short ripening period in fermented sausages was associated with greater survival of $L$. monocytogenes ( Gonzales-Barron et al., 2015; Nightingale et al., 2006) and that the length of the drying period may be particularly important in the control of $L$. monocytogenes. Reynolds et al. (2001) found that in dry-cured ham $L$. monocytogenes populations continued to decline to undetectable levels after the hams completed the dry-aging process highlighting the importance of ageing in the control of L. monocytogenes.

In the present study, after HPP treatment at $593 \mathrm{MPa}$ for $290 \mathrm{sec}$., a reduction of 0.47 $1.41 \log \mathrm{CFU} / \mathrm{g}$ and 1.63-3.54 log CFU/g on surface and in depth respectively; there are no data in literature on HPP of coppa to compare our results. In studies regarding HPP treatment of fermented dry meat products at time/pressure parameters similar to those applied in this study, a 1.6-5.0 Log $\mathrm{CFU} / \mathrm{g}$ reduction at $600 \mathrm{MPa}$ for $5 \mathrm{~min}$ in Genoa salami (Porto-Fett et al., 2010), a 1.79-3.15 Log CFU/g reduction in Spanish chorizo at $600 \mathrm{MPa}$ for 5-10 minutes (Rubio et al., 2018) and a $0.9 \mathrm{Log} \mathrm{CFU} / \mathrm{g}$ reduction in slightly fermented sausages at $400 \mathrm{MPa}$ for 10 minutes (Garriga et al., 2005) were reported.

Various authors have tested the inactivation of $L$. monocytogenes in other unfermented meat products by HPP (Garriga et al., 2004; Hugas et al., 2002; Merialdi et al., 2015), many of them in dry-cured ham (Morales et al., 2006; Bover-Cid et al., 2011; Hereu et al., 2012; Bover-Cid et al., 2015): Hereu et al. (2012) have reported a reduction of L. monocytogenes from 1.82 to $3.85 \mathrm{log}$ $\mathrm{CFU} / \mathrm{g}$ in artificially contaminated sliced ham after treatment at $600 \mathrm{MPa}$ for $5 \mathrm{~min}$, Bover-Cid et al. (2011), through a HPP treatment at $613 \mathrm{MPa}$ for $5 \mathrm{~min}$., achieved the 2.39D proposed by Hoz et al. (2008) to meet the USA zero tolerance policy, BoverCid et al. (2015) showed a reduction of $L$. monocytogenes in dry-cured ham at $600 \mathrm{MPa}$ for 5 minutes ranging from $2.24 \log$ to 6.82 Log CFU/g depending on the $a_{w}$ and fat content of the ham.

In our study a general lower effect on $L$. innocua count reduction was observed probably due to variables as a result of intrinsic characteristics of the product $(\mathrm{pH}$, $a_{w}$, fat, protein and solute content) that influence the efficacy of HPP treatment on Listeria spp.; also the different bacterial baroresistance of different strains used in different studies should be taken into account (Possas et al., 2017).

Table 4. Logarithmic unit reductions of L. innocua $(\mathrm{L})$ in superficial and deep samples after each sampling step.

\begin{tabular}{|c|c|c|c|c|c|c|c|c|}
\hline & \multicolumn{2}{|c|}{ Company A } & \multicolumn{2}{|c|}{ Company B } & \multicolumn{2}{|c|}{ Company C } & \multicolumn{2}{|c|}{ Company D } \\
\hline & $L_{\text {Sup }}$ & $L_{\text {Deep }}$ & $L_{\text {Sup }}$ & $L_{\text {Deep }}$ & $L_{\text {Sup }}$ & $L_{\text {Deep }}$ & $L_{\text {Sup }}$ & $L_{\text {Deep }}$ \\
\hline Resting - $\Delta$ (T0-T1) & 0.46 & - & 1.39 & - & 1.52 & - & 1.82 & - \\
\hline Drying and Ripening - $\Delta$ (T1-Tend $)$ & 2.80 & 0.93 & 1.61 & 0.03 & 1.37 & 0.57 & -1.84 & -2.23 \\
\hline Production process - $\Delta$ (T0-Tend $)$ & 3.26 & - & 3.00 & - & 2.89 & - & -0.02 & - \\
\hline HPP - $\Delta$ (Tend-THPP) & 0.47 & 2.57 & 0.74 & 2.52 & 1.41 & 1.63 & 0.94 & 3.54 \\
\hline TOTAL - $\triangle(\mathrm{T} 0-\mathrm{T} H P P)$ & 3.73 & - & 3.74 & - & 4.30 & - & 0.92 & - \\
\hline
\end{tabular}


However, the results of this study confirm that using a HPP treatment can be an effective supplemental intervention strategy for controlling L. monocytogenes contaminations in dry-cured meat products such as coppa. Nevertheless, being HPP effectiveness strongly dependent on product's characteristics, it remains necessary to set and validate HPP treatment conditions on each specific food product due to its uniqueness in composition and manufacturing process.

For products intended for exportation to countries with zero tolerance policy for Listeria, in particular the United States, HPP treatment used as a post-production process for sanitation, resulted to be a decisive factor to achieve the USDA/FSIS requirement. According to the data reported in this paper, processes of companies $\mathrm{A}, \mathrm{B}$, and $\mathrm{C}$ resulted able to reduce $L$. innocua contamination, and HPP treatment increases the ability in reducing $L$. innocua count with the objective of a lethality treatment. For company D an increase of $L$. innocua count during the process and HPP failed in reaching the superficial Listeria inactivation requirements needed for exportation of dry-cured meat in the U.S. Processors should assess the ability of their process to control incoming pathogens, to predict the L. innocua load at the end of the process, and to evaluate the need for a process modification and/or for the addition of a final lethal process.

\section{References}

Barbuti S, Grisenti M, Frustoli M, Parolari $\mathrm{G}, 2009$. Validation of the manufacturing process of Italian dry-cured ham (prosciutto) for the inactivation of Listeria monocytogenes and Salmonella spp. Int Congr Meat Sci Technol PE6.10.

Black EP, Huppertz T, Fitzgerald GF, Kelly AL, 2007a. Baroprotection of vegetative bacteria by milk constituents: A study of Listeria innocua. Int Dairy J 17:104-10. doi: 10.1016/j.idairyj.2006.01.009.

Black EP, Setlow P, Hocking AD, Stewart CM, Kelly AL, Hoover DG, 2007b. Response of spores to high-pressure processing. Compr Rev Food Sci Food Saf 6:103-119.

Bonilauri P, Liuzzo G, Merialdi G, Bentley S, Poeta A, Granelli F, Dottori M, 2004. Growth of Listeria monocytogenes on vacuum-packaged horsemeat for human consumption. Meat Sci 68:671-4.

Bover-Cid S, Belletti N, Aymerich T, Garriga M, 2015. Modeling the protective effect of a $\mathrm{w}$ and fat content on the high pressure resistance of Listeria monocytogenes in dry-cured ham. Food
Res Int 75:194-9.

Bover-Cid S, Belletti N, Garriga M, Aymerich T, 2011. Model for Listeria monocytogenes inactivation on drycured ham by high hydrostatic pressure processing. Food Microbiol 28:804-9.

Busconi M, Zacconi C, Scolari G, 2014. Bacterial ecology of PDO Coppa and Pancetta Piacentina at the end of ripening and after MAP storage of sliced product. Int J Food Microbiol 172:1320.

EFSA, 2010. Management of left-censored data in dietary exposure assessment of chemical substances EFSA J 8:1557

EFSA and ECDC, 2019. The European Union One Health 2018 Zoonoses Report. EFSA J. 17:5926, 276.

European Commission, 2005. Commission Regulation (EC) No 2073/2005 of 15 November 2005 on microbiological criteria for foodstuffs. OJ EU:1-26.

Food Safety and Inspection Service/ United States Department of Agricultural (USDA/FSIS), 2017. FSIS Salmonella Compliance Guidelines for Small and Very Small Meat and Poultry Establishments that Produce Ready-toEat (RTE) Products and Revised Appendix A.

Food Safety Inspection Service (FSIS), 2015. Control of Listeria monocytogenes in ready-to-eat meat and poultry products. Fed Regist 80:3517835188.

Garriga M, Grèbol N, Aymerich MT, Monfort JM, Hugas M, 2004. Microbial inactivation after high-pressure processing at $600 \mathrm{MPa}$ in commercial meat products over its shelf life. Innov Food Sci Emerg Technol 5:451-7.

Garriga M, Marcos B, Martín B, VecianaNogués MT, Bover-Cid S, Hugas M, Aymerich T, 2005. Starter cultures and high-pressure processing to improve the hygiene and safety of slightly fermented sausages. J Food Prot 68:2341-8.

Gonzales-Barron U, Cadavez V, Pereira AP, Gomes A, Araújo JP, Saavedra MJ, Estevinho L, Butler F, Pires P, Dias T, 2015. Relating physicochemical and microbiological safety indicators during processing of linguiça, a Portuguese traditional dry-fermented sausage. Food Res Int 78:50-61.

Gray JA, Chandry PS, Kaur M, Kocharunchitt C, Bowman JP, Fox EM, 2018. Novel biocontrol methods for Listeria monocytogenes biofilms in food production facilities. Front Microbiol 9:605.

Hayman MM, Kouassi GK, Anantheswaran RC, Floros JD, Knabel SJ, 2008. Effect of water activity on inactivation of
Listeria monocytogenes and lactate dehydrogenase during high pressure processing. Int $\mathrm{J}$ Food Microbiol 124:21-6.

Hereu A, Bover-Cid S, Garriga M, Aymerich T, 2012. High hydrostatic pressure and biopreservation of dry-cured ham to meet the Food Safety Objectives for Listeria monocytogenes. Int J Food Microbiol 154:107-12.

Hoz L, Cambero MI, Cabeza MC, Herrero AM, Ordóñez JA, Ordón O, Ordóñez O, 2008. Elimination of Listeria monocytogenes from Vacuum-Packed Dry-Cured Ham by E-Beam Radiation doi: 10.4315/0362-028X-71.10.2001.

$\mathrm{Hu}$ M, Gurtler JB, 2017. Selection of surrogate bacteria for use in food safety challenge studies: A review. J Food Prot 80:1506-36.

Hugas M, Garriga M, Monfort JM, 2002. New mild technologies in meat processing: High pressure as a model technology. Meat Sci 62:359-71.

ISO, 2004. Microbiology of food and animal feeding stuffs - Horizontal method for the detection and enumeration of Listeria monocytogenes - Part 1: Detection method AMENDMENT 1: Modification of the isolation media and the haemolysis test, and inclusion of precisiondata. ISO 11290-1:1996/AMD 1:2004.

ISO, 2004. Microbiology of food and animal feeding stuffs. Determination of water activity ISO 21807:2004.

Jordan K, McAuliffe O, 2018. Listeria monocytogenes in Foods. Adv Food Nutr Res 86:181-213.

Meloni D, Galluzzo P, Mureddu A, Piras F, Griffiths M, Mazzette R, 2009. Listeria monocytogenes in RTE foods marketed in Italy: Prevalence and automated EcoRI ribotyping of the isolates. Int $\mathrm{J}$ Food Microbiol 129:166-73

Merialdi G, Ramini M, Ravanetti E, Gherri G, Bonilauri P, 2015. Reduction of listeria innocua contamination in vacuum-pack-aged dry-cured italian pork products after high hydrostatic pressure treatment. Ital $\mathrm{J}$ Food Saf 4:101-3.

Montiel R, Peirotén Á, Ortiz S, Bravo D, Gaya P, Martínez-Suárez J V., Tapiador J, Nuñez M, Medina M, 2020. Inactivation of Listeria monocytogenes during dry-cured ham processing. Int $\mathrm{J}$ Food Microbiol 318:108469.

Morales P, Calzada J, Nuñez M, 2006. Effect of high-pressure treatment on the survival of Listeria monocytogenes Scott A in sliced vacuum-packaged Iberian and Serrano cured hams. J Food Prot 69:2539-43. 
Morales-Partera ÁM, Cardoso-Toset F, Jurado-Martos F, Astorga RJ, Huerta B, Luque I, Tarradas C, Gómez-Laguna J, 2017. Survival of selected foodborne pathogens on dry-cured pork loins. Int $\mathrm{J}$ Food Microbiol 258:68-72.

Nightingale KK, Thippareddi H, Phebus RK, Marsden JL, Nutsch AL, 2006. Validation of a traditional Italian-style salami manufacturing process for control of Salmonella and Listeria monocytogenes. J Food Prot 69:794800.

Patterson MF, 2005. Microbiology of pressure-treated foods. J Appl Microbiol 98:1400-9.

Porto-Fett ACS, Call JE, Shoyer BE, Hill DE, Pshebniski C, Cocoma GJ, Luchansky JB, 2010. Evaluation of fermentation, drying, and/or high pressure processing on viability of Listeria monocytogenes, Escherichia coli O157:H7, Salmonella spp., and Trichinella spiralis in raw pork and Genoa salami. Int J Food Microbiol 140:61-75.

Possas A, Pérez-Rodríguez F, Valero A,
García-Gimeno RM, 2017. Modelling the inactivation of Listeria monocytogenes by high hydrostatic pressure processing in foods: A review. Trends Food Sci Technol 70:45-55.

Rastogi NK, Raghavarao KSMS, Balasubramaniam VM, Niranjan K, Knorr D, 2007. Opportunities and Challenges in High Pressure Processing of Foods. Crit Rev Food Sci Nutr 47:69112.

Reynolds AE, Harrison MA, Rose-Morrow R, Lyon CE, 2001. Validation of Drycured Ham Process for Control of Pathogens. J Food Sci 66:1373-9.

Rubio B, Possas A, Rincón F, GarcíaGímeno RM, Martínez B, 2018. Model for Listeria monocytogenes inactivation by high hydrostatic pressure processing in Spanish chorizo sausage. Food Microbiol. 69:18-24.

Sandra S, Stanford MA, Goddik LM, 2004. The Use of High-pressure Processing in the Production of Queso Fresco Cheese. J Food Sci. 69:FEP153-FEP158.

Tack DM, Marder EP, Griffin PM, Cieslak PR, Dunn J, Hurd S, Scallan E, Lathrop
S, Muse A, Ryan P, et al., 2019. Preliminary incidence and trends of infections with pathogens transmitted commonly through food - foodborne diseases active surveillance network, 10 U.S. sites, 2015-2018. Morb Mortal Wkly Rep. 68:369-373.

Tao Y, Hogan E, Kelly AL, 2014. Chapter 1 - High-Pressure Processing of Foods: An Overview. In: Emerg Technol Food Process. Elsevier; p. 3-24.

Van Hekken DL, Tunick MH, Farkye NY, Tomasula PM, 2013. Effect of hydrostatic high-pressure processing on the chemical, functional, and rheological properties of starter-free Queso Fresco1. J Dairy Sci 96:6147-60.

Zanardi E, Novelli E, Ghiretti GP, Chizzolini R, 2000. Oxidative stability of lipids and cholesterol in salame Milano, coppa and Parma ham: Dietary supplementation with vitamin $\mathrm{E}$ and oleic acid. Meat Sci 55:169-175.

Zhang H, Mittal GS, 2008. Effects of Highpressure Processing (HPP) on bacterial spores: An overview. Food Rev Int 24:330-51. 